\title{
Pediatric thoracic outlet syndrome proven by arterial blood pressure monitoring during general anesthesia: a case report
}

\author{
Hidekazu Ito ${ }^{*}$ D and Shoji Mizuno
}

To the Editor,

Thoracic outlet syndrome (TOS) is a group of disorders that occur when blood vessels or nerves in the space between the clavicle and the first rib (thoracic outlet) are compressed [1]. While TOS usually occurs in women and young adults, we experienced a pediatric case during general anesthesia.

A 9-year-old boy (height $127 \mathrm{~cm}$, weight $18.6 \mathrm{~kg}$ ) was bedridden due to sequelae of neonatal-onset medium-chain acyl-CoA dehydrogenase deficiency (MCADD). Femoral osteotomy and selective muscle release of the hip and the knee were planned for hip dislocation and joint contracture. The procedure was successfully completed under general and epidural anesthesia with standard monitoring and invasive arterial blood pressure (ABP) monitoring of the left radial artery. When both upper extremities were abducted to fix the cast on the lower extremities, the ABP suddenly decreased from $77 / 37$ to $29 / 23$ $\mathrm{mmHg}$. Hypovolemia was suspected, and a bolus of hydroxyethyl starch was administered. While a 180 $\mathrm{mL}(10 \mathrm{~mL} / \mathrm{kg})$ bolus was not effective, the ABP improved when the left upper extremity was returned to its place. Since this phenomenon was repeatedly recognized, we performed left axillary artery ultrasonography. The results are shown in Fig. 1. The pressure waveform of the radial artery was lost only when the left upper extremity was abducted with ex- ternal rotation, resulting in a diagnosis of TOS. No complications occurred during the emergence from general anesthesia, and the patient returned to the general ward.

TOS is divided into three types as follows: (i) neurogenic, (ii) vascular, and (iii) non-specific [1]. The signs and symptoms of neurogenic TOS include numbness or pain on the upper extremities and weakening grip. In contrast, symptoms of vascular TOS include discoloration, pain, swelling, and weak or no pulse in the affected upper extremities. The lack of a Doppler signal of the axillary artery indicates vascular TOS. Neurogenic TOS may also exist, as the subclavian artery and brachial plexus run through the same "thoracic outlet". Since the present patient is lean and lacks supporting tissue due to the sequelae of MCADD, the range of the shoulder joint motion has expanded.

The diagnosis of vascular TOS with ultrasonography has yet to be established. The typical findings include a lack of a Doppler signal and increased echogenicity of the vascular lumen on grayscale images [2]. However, these findings may also be seen in normal patients. In addition, his inability to communicate verbally made it impossible to assess his symptoms. While computed tomography and magnetic resonance imaging were not performed because of no surgical indication, the lack of the

* Correspondence: oniheizo1745@gmail.com

Department of Anesthesiology, Aichi Developmental Disability Center Central Hospital, 713-8 Kagiya-cho, Kasugai-City, Aichi 480-0392, Japan 


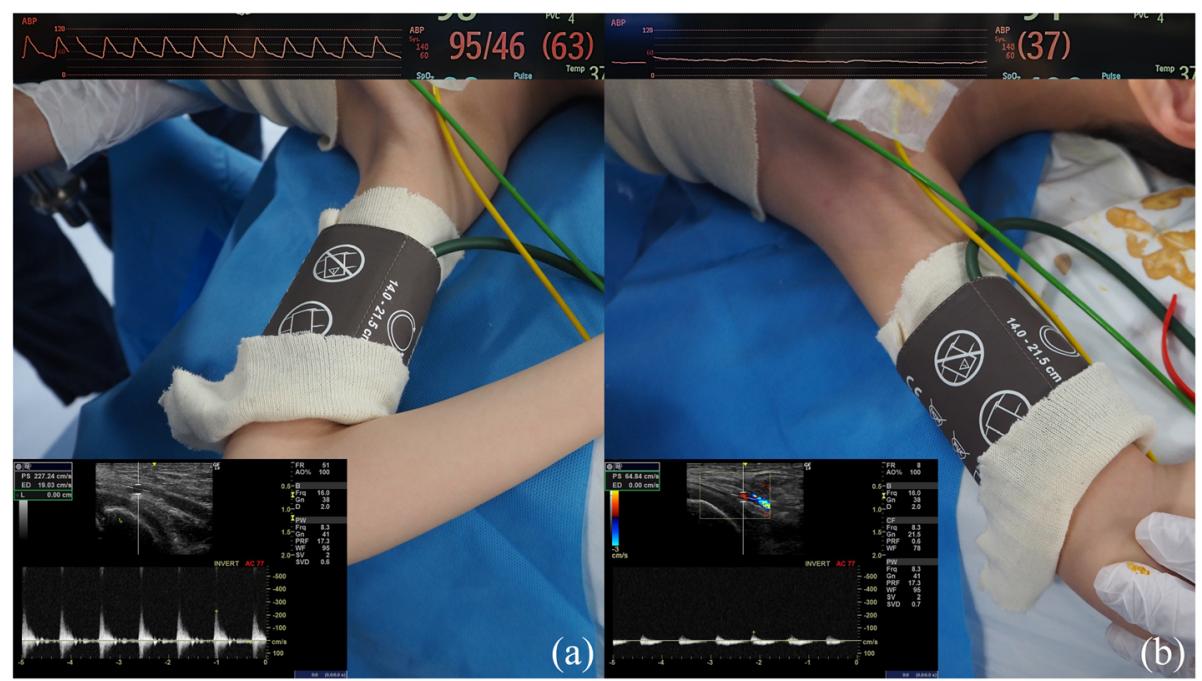

Fig. 1 Change in the radial and axillary arterial flow. a Slightly abducted position: the pressure waveform of the radial artery and Doppler signal of the axillary artery exist. $\mathbf{b}$ Excessive abducted position with external rotation: the pressure waveform of the radial artery and Doppler signal of the axillary artery have disappeared

pressure waveform of the radial artery and a Doppler signal of the axillary artery strongly suggested vascular TOS.

The upper extremities are sometimes abducted during pediatric general anesthesia. Pediatric anesthesiologists should take special care to avoid excessive abduction with external rotation to prevent postoperative neurological defects. In cases without ABP monitoring, pediatric anesthesiologists need to observe the pulse oximetry waveform of upper extremities carefully and consider the possibility of TOS when it disappears.

\section{Abbreviations}

TOS: Thoracic outlet syndrome; MCADD: Medium-chain acyl-CoA dehydrogenase deficiency

\section{Acknowledgements}

Dr. Kenji lio of the Department of Anesthesiology and Dr. Hironori Ito of the Department of Orthopedics, in Aichi Developmental Disability Center Central Hospital, gave us general suggestions regarding thoracic outlet syndrome. Dr. Kazuya Sobue, Professor of Anesthesiology and Intensive Care Medicine, Nagoya City University, corrected our manuscript. We thank Brian Quinn from Japan Medical Communication (https://www.japan-mc.co.jp) for editing a draft of this manuscript.

\section{Authors' contributions}

$\mathrm{HI}$ and SM performed anesthetic management. HI also drafted the article. Both authors read and approved the final manuscript.

\section{Funding}

None of the authors received any funding.

\section{Availability of data and materials}

Please contact the first author to obtain the data of this article.

\section{Consent for publication}

Written informed consent was obtained from the parents of this patient for the publication of this case report and any accompanying images.

\section{Competing interests}

The authors declare that they have no competing interests.

Received: 15 June 2020 Accepted: 8 July 2020

Published online: 16 July 2020

\section{References}

1. Mayo Clinic. Thoracic outlet syndrome. 2020. https://www.mayoclinic.org/ diseases-conditions/thoracic-outlet-syndrome/symptoms-causes/syc-20353 988. Accessed 15 Jun 2020

2. Raptis CA, Sridhar S, Thompson RW, Fowler KJ, Bhalla S. Imaging of the patient with thoracic outlet syndrome. Radiographics. 2016:36:984-1000.

\section{Publisher's Note}

Springer Nature remains neutral with regard to jurisdictional claims in published maps and institutional affiliations.

\section{Submit your manuscript to a SpringerOpen ${ }^{\circ}$ journal and benefit from:}

- Convenient online submission

- Rigorous peer review

- Open access: articles freely available online

High visibility within the field

- Retaining the copyright to your article

Submit your next manuscript at $\boldsymbol{\triangleright}$ springeropen.com 